\title{
Networked Flow: A Framework for Understanding the Dynamics of Creative Collaboration in Educational and Training Settings
}

\author{
Andrea Gaggioli ${ }^{*}$, Luca Milani $^{2}$, Elvis Mazzoni $^{3}$ and Giuseppe Riva ${ }^{1}$ \\ ${ }^{I}$ Department of Psychology, Catholic University of Milan, Italy \\ ${ }^{2}$ Department of Psychology - CRiDEE, Catholic University of Milan, Italy \\ ${ }^{3}$ Educational Science Department “Giovanni Maria Bertin”, University of Bologna, Italy
}

\begin{abstract}
Supporting creative collaboration in the classroom is considered an important objective by current education research, as growing evidence suggests that this practice is linked with the quality of learning and the development of problem solving skills. Drawing on recent advances in group creativity research, social cognition and network science, we propose a theoretical framework for studying creative collaboration that integrates the concepts of group flow and social presence. Our key hypothesis is that in order for a group to enter the creative state of flow, members must be able to develop a "we-intention", in which the actions of the individuals and those of the collective are merged (social presence). According to our model, this is a staged process, beginning with the co-construction of a shared frame within the group and culminating with the creation of a novel artefact or concept. A further assumption is that the emergence of such optimal group state is associated with structural changes in the dynamics of group interaction, which can be effectively investigated using social network analysis techniques.
\end{abstract}

Keywords: Creative collaboration, group creativity, group flow, zone of proximal development, social presence, social network analysis.

\section{INTRODUCTION}

In the post-industrial world, information technology is catalysing the shift from a production-based economy to a knowledge-based economy, where the generation of new knowledge and innovation are considered as key driver to growth and prosperity [1]. In this new economy, an increasing number of careers require strong teamwork and collaboration abilities, which involve collective problem solving, applications of specialized expertise and high communication skills. As a consequence, the definition of effective methods to support knowledge creation and the ability to work effectively as part of a team has become a significant challenge in educational settings [2,3]. As Seltzer and Bentley pointed out [4], a transformation is needed in order to enable the education system to generate creative citizens that are flexible, productive and able to operate effectively in the new economy of intangibles. The development of creative collaboration skills in the classroom is not only important because of the team-oriented nature of the modern work environment, but also because there is evidence that learning performance is enhanced when students are engaged in tasks that involve social interactions [5-7]. In particular, previous research has shown that cooperation is an effective way of structuring learning when compared to other types of social interactions, such as competition and individualism [8]. Collaborative creativity activities allow students to engage, share their opinions and negotiate their viewpoints. Examples of such practices

*Address correspondence to this author at the Department of Psychology of the Catholic University of Milan, at Largo Gemelli 1, 20123, Milan, Italy; Tel: +39 027234 3734; E-mail: andrea.gaggioli@unicatt.it include planning together, language play, musing, singing, humor, acting out, and role-playing games [9]. However, there is still limited understanding about the key aspects that facilitate (or obstacle) effective cooperation and creative engagement in learning contexts [10]. Recently, psychologist and educator Keith Sawyer introduced the concept of "group flow" as the key to creative collaboration, describing it as "a collective state of mind (...) a peak experience, a group performing at its top level of ability" [11, p. 43]. He identified several conditions which facilitate the occurrence of this experience. These include the definition of a common mission, the development of close listening skills, the ability for the team to construct a well-defined and stable identity, and the capacity of "blending the egos", which is achieved when the group is in perfect harmony and the barriers between individual intention and collective intention disappear. In the present article, we build on and extend Sawyer's work on group creativity and flow along three key directions. First, we theorize that group flow is a peak creative state that is achieved when members of the team experience high levels of social presence. In this context, we regard social presence as a process that leads the group to develop a "we-intention", in which actions of the individuals and those of the collective are in balance, and a sense of mutual trust, sharing and empathy is established. Moreover, we argue that when such optimal collective experience is reached, group-level emotions are shared and embodied in novel and useful ideas.

Second, we describe the development of optimal group creativity as a staged process, which begins with the coconstruction of a shared frame and culminates with the creation of a novel artefact or concept. In our view, the 
relationship between the process (group collaboration) and the product (the emergence of a novel artefact or idea) is a bi-directional one: the creative product affects the structure of the frame, which in turns affects the unfolding of meaning. Similarly to stigmergic interaction, in which agents coordinate actions by making and sensing changes to a shared environment [12], the creative product provides an extra-somatic memory of group interactions and emotions, which ultimately shapes the complex dynamics of team interaction. Third, we argue that the emergence of optimal group experience is associated with structural changes in group dynamics, which can be effectively investigated using social network analysis techniques.

The article is organized as follows. The first part provides a through analysis of the key theoretical concepts and terms. In the second section, the networked flow model is described in its cognitive, psychological and methodological components. The final part of the article discusses the potential applications of the model for studying creative learning teams, and provides future directions for research.

\section{KEY CONCEPTS AND TERMS}

From a socio-cultural perspective, learning and creativity are closely connected phenomena. Both processes are regarded as situated activities that imply collaborative meaning-making and knowledge construction [10]. The Soviet psychologist, Vygotsky [13] suggested that when children are learning a new activity, they look up to those with more experience for guidance in a process called the Zone of Proximal Development, or ZDP. According to Vygotsky, ZDP is "the distance between the actual developmental level as determined by independent problem solving and the level of potential development as determined through problem solving under adult guidance, or in collaboration with more capable peers" [13, p. 86]. JohnSteiner and Mahn [14] further elaborated Vygotsky's conceptualization, emphasizing how the participation with group activities allows collective knowledge to be shared among individuals and its eventual internalization in the individual's consciousness. In the view of these authors, "internalization is simultaneously an individual and a social process. In working with, through, and beyond what they have appropriated in social participation and then internalized, individuals coconstruct new knowledge. In contrast to facile internalization, which leads to a limited combination of ideas, internalization that involves sustained social and individual endeavors becomes a constituent part of the interaction with what is known and leads to the creation of new knowledge" (p. 197). Previous research suggests that high levels of engagement, enjoyment and positive emotional states play a crucial role in fostering creative collaboration in the learning settings $[10,15]$. In particular, it has been argued that co-creation, sharing and transmission of knowledge inside a group can be fostered when its members reach a state of optimal experience, or flow $[15,16]$. The concept of flow was introduced by Csikszentmihalyi [17, 18], who described it as a state of consciousness characterized by global positivity and a high level of complexity, in which the perception of a higherthan-average opportunities for action (challenges) is coupled with the perception of appropriate skills. Other peculiar characteristics of this experience include high levels of concentration and involvement in the task at hand, enjoyment, a positive affective state and intrinsic motivation. Furthermore, during flow there is a complete fusion between action and awareness, and the individual feels complete control over his own actions and environment. A number of studies indicate that flow shows constant features at the cross-cultural level, and it can be associated with various daily activities, provided that individuals perceive them as complex opportunities for action and involvement [19].

The concept of flow is considered particularly relevant to the investigation of learning processes, and several scholars have investigated the specific factors fostering optimal experience in education [16, 20-25]. While Csikszentmihalyi investigated flow mainly at the individual level, Sawyer [11, 15] extended this concept to the study of group collaboration, with the purpose of understanding which features facilitate optimal group experience and its relationship with creative performance. To this end, Sawyer [11] analyzed in detail the behavior of teams in different creative areas (the theatre, jazz), and found that successful teams were distinguished by their ability to reach "a collective state of mind (...) a peak experience, a group performing at its top level of ability" (p. 43). He also identified several conditions which facilitate the occurrence of this optimal state (pp. 44-57):

the group's goal: group flow develops more easily if the group members share an understanding of the objectives to be achieved together;

close listening: it is important to develop good listening skills in order to harmonize with team members: this requires focusing on the content of what the others are saying, and reviewing the relevant information;

complete concentration: group flow is facilitated when the group is able to draw a boundary between its activities and everything else occurs;

being in control: optimal group experience is likely to increase when team members feel autonomy, competence, and mutual connection;

- blending egos: to reach group flow, participants must have the ability to submerge their egos to the group mind, to balance their own voices with deep listening; this is the key moment when the group is in perfect harmony and the barriers between individual intention and collective intention disappear;

equal participation: optimal group experience is more likely to occur when all participants play an equal role in the creation of the final performance;

familiarity: a group is more likely to reach a state of flow if members of the team know the performance styles of their teammates and their opponents. This characteristic, which is necessary to develop implicit knowledge, is acquired as the experience continues through time;

communication: in order for group flow to come about, constant communication is required, preferably spontaneous and informal; 
moving it forward: this condition calls for the ability to build on the ideas of others, making the most of the ideas and abilities of all group members in order to tackle and overcome any difficulties;

the potential for failure: group flow is more likely to occur when there is the potential for failure, whereas it is less likely in 'safe' situations where mistakes do not affect the consequences.

According to Sawyer, group flow is a collective state of mind which "cannot be reduced to psychological studies of the mental states or the subjective experiences of the individual members of the group" $[15$, p. 46]. In other words, group flow cannot be broken down into the work of individuals: it is a phenomenon which emerges from the interactions occurring within a group, and which is able to positively influence overall performance. Furthermore, Sawyer holds that the achievement of group flow involves a balance between the extrinsic/intrinsic nature of the goal and pre-existing structures shared by the team members (for example know-how, instructions, repertory of cultural symbols, set of tacit practices etc.). An extrinsic goal, according to Sawyer, is characterized by a specific and welldefined objective (i.e. how to fix a bug in a software) and therefore requires more shared structures to be achieved. In contrast, an intrinsic goal is largely unknown and undefined (i.e. the task faced by an improvisation group in theatre) and therefore it requires less shared structures to be achieved [15, p. 167].

Sawyer suggests that the group flow concept can be applied in several collaborative settings, including those occurring in educational contexts [15]. This latter line of research has been further developed by Armstrong [16], who conducted a study in order to examine the conditions which foster (or hinder) the emergence of optimal group experience in middle school mathematics classroom setting. According to Armstrong, the occurrence of group flow is indicative that the team is working in a collaborative zone of proximal development, which the author defines as "an intellectual site where students are able first to negotiate shared meaning within their group (or part of their group)" (p. 102). In particular, the author drew on the complex systems model of mathematics classes developed by Davis and Simmt [26] to identify a set of specific conditions that leads to the establishment of such "space of joint actions" which are, namely: (a) internal diversity: the provision of diversity of ideas that permits innovation; (b) redundancy: the creation of a common ground shared by group members which provides internal coherence to the interaction; (c) decentralized control: the situation in which the actions of a group and the decisions that it takes are shared and distributed and not managed by a single member; (d) organized randomness: the functional balance between redundancy and diversity; and (e) neighbor interactions: the exchange and combination of ideas [16, p. 102]. The study consisted in the observation of the working processes of two small groups of students collaborating on a problem-solving task; sessions were recorded using videotapes and written transcripts. To identify the occurrence of group flow, Armstrong focused on specific physical and verbal behaviors, which would indicate a synchronization of actions and thoughts (i.e., physical closeness, echoing of gestures and phrases, the mirroring of each other's physical actions). The study found that although both groups had the prerequisite structures in place to experience group flow, only one group showed the characteristics of this optimal state. According to Armstrong, the absence of group flow in the second group could be explained by a lower level of decentralization, due to the fact that one student took the lead and presented the group with a solution which was passively accepted by the other team members throughout the discussion. As a consequence, some members of this group failed to establish a working collaborative proximal zone of development, in which they could develop their ideas collectively. Armstrong used these findings to draw implications for practice. For example, according to the author it is important to assign students to group "where they feel high level of comfort and trust so that all members feel safe to contribute and develop a collective zone of proximal development" [16, p. 114]. Furthermore, the author stresses the importance of the level of student's ability when creating a group: low-level and high-level students should be given equal opportunities to contribute to the discussion and find common level of understanding. Another important factor that facilitates the occurrence of group flow is the possibility for all group members to provide each other with quick and meaningful feedback, thus avoiding that a more expert student takes the lead and guides the rest of the team.

\section{FROM "GROUP FLOW" TO "NETWORKED FLOW": THE ROLE OF SOCIAL PRESENCE IN CREATIVE LEARNING TEAMS}

Optimal group flow is increasingly regarded as a key aspect to understand group creativity in collaborative learning settings. A limitation of the group flow model, however, is that this concept has been analyzed mainly from a phenomenological perspective, whereas there is lack of discussion about its cognitive dimensions. For example, Armstrong [16] argues that the development of a collaborative zone of proximal development, which allows students to negotiate shared meaning within their group, is a precondition for the occurrence of group flow. However, the mental processes underlying this "space of joint action" and their relationships with optimal group experience have not been investigated in depth. Furthermore, previous research on group flow in creative collaboration settings has focused on the specific conditions that facilitate (or hinder) the occurrence of this experience $[11,15,16]$. On the other hand, less attention has been devoted to the analysis of the evolutive dynamics that supports the emergence of an optimal creative state. From the methodological perspective, a limitation of the group flow model is that this approach has been mostly used to investigate face-to-face collaborative interaction settings. However, the application of the group flow model for studying creative collaboration in blended learning environments, where online interactions and faceto-face interactions are combined in the same course, presents new challenges and questions for researchers. For example, according to the group flow theory, the synchronization of action and thoughts (i.e. physical closeness, echoing of gestures and phrases) is an important dimension of the group flow experience. How is this synchronization achieved within virtual collaborative environments? Is physical co-presence a pre-requisite for 
optimal team experience? And what happens to group flow when the other members of the team are not physically, but only virtually present, such as in a chat room? The concepts of "presence" and "social presence" provide a useful starting point to address these issues. The term "presence" entered in the wide scientific debate in 1992 when Sheridan and Furness used it in the title of a new journal dedicated to the study of virtual reality systems and teleoperations: Presence, Teleoperators and Virtual Environments. However, as commented by Biocca [27], and agreed by most researchers in the area, "while the design of virtual reality technology has brought the theoretical issue of presence to the fore, few theorists argue that the experience of presence suddenly emerged with the arrival of virtual reality" (p. 121). So, what is presence? the recent contributions of cognitive sciences suggest that presence and social presence are broad psychological phenomena, not necessarily linked to the experience of a medium, whose goal is the control of the individual and social activity. According to Gamberini, Spagnolli and Mantovani, the sense of presence is linked to a subject's capacity for action and his ability to position himself within his physical and social space [28-30]. More precisely, for Spagnolli and Gamberini [29]: "Presence is the feature of the agent which is manifested through the creation of a space during action" (p. 8). A similar, but broader view, was recently outlined by Riva and Waterworth [31-33]. The idea proposed by the two authors is the following: presence can be described as a selective and adaptive mechanism which allows to define the boundaries of action by means of the distinction between "internal" and "external" within the sensory flow. In other words, from an evolutionary point of view, presence has three functions:

- To permit the subject to position himself in a space real, virtual or social - through the distinction between "internal" and "external" and the definition of a boundary;

- $\quad$ To check the efficacy of the subject's actions through the comparison of intention and the result of the action;

- To allow its own evolution through the identification of "optimal experiences" (flow) and the incorporation of the artifacts - physical and social - linked to it.

In other words, because of presence, an individual is able to situate himself in a physical and social space by defining his own boundaries.

The concept of presence concerns the subject and his or her ability to act in the world: I am present in a real or virtual space if I manage to put my intentions into action. But how does one connect to the Other? How does the Other become present for the subject? To answer this question we will analyze the implications of the recent discovery of the "mirror" neurons.

These neurons, discovered in the ventral pre-motor cortex of apes (area F5), have, amongst other qualities, that of activating not only when the animal performs a given action, but also when the animal sees another animal - man or ape - performing the same action $[34,35]$. Therefore, the individual who observes is able to put himself "in the shoes of the actor": I am able to understand what the another is doing because when I watch him I experience, completely intuitively, the same neuron activity as when I perform that action. This means that at neural level, the action performed and the action observed both are codified in a multisubjective format, which does not recognize actor or observer. This process is, however, effective if the subject is capable of distinguishing between an action performed and an action perceived. This suggests the existence of a second selective and adaptive mechanism, social presence, which enables the Self to identify and interact with the Other by understanding his intentions. In other words, from an evolutionary point of view, social presence has three functions:

- To enable the subject to identify the Other and to attribute to him an ontological status - "the other similar to the self" - different from the other objects perceived;

- To allow interaction and communication through the understanding of the Other's intentions;

- To permit the evolution of the intentionality of the Self (from the body, to the external world, to the possible world) [36] through the identification of group-based "optimal experiences" (Networked Flow) and the incorporation of artifacts - physical and social - linked to them.

Starting from these premises, we theorize that group flow is the result of the association between a situation of "liminality" (definable as a state of transit, of "being about to") and maximum levels of presence and social presence. In order to reach this optimum collective status, it is necessary that group members experience a high level of social presence: the feeling of sharing one's own goals and emotions with others. On the other hand, it is also necessary that the members of the group also experience a situation of liminality and that within the group, they find the means to overcome it. It is during this experience that the group creates and shares new meanings and new intentions. In the following paragraph we will endeavor to justify these claims.

\section{THE SIX-STAGED MODEL OF NETWORKED FLOW}

In the previous paragraph, we have argued that the experience of high levels of social presence is an important pre-condition for achieving group flow. We theorize that the progression towards social presence and optimal group performance requires the completion of several sub-phases, each of them characterized by clearly distinguishable characteristics. Drawing on previous research on collaborative creativity and group cognition, as well as from data collected in realistic collaborative settings, we have identified six key stages that lead to the completion of this process.

\section{Phase 1: Meeting (Persistence)}

The first phase in the emergence of networked flow, Persistence, can take place in any social environment in which there are a certain number of individuals who share an interactive context. Referring to Goffman [37], we can define this interactive context as a frame, that is, an area of inter-subjective expression which is in some way shared by the participants. Each person in the frame possesses their own individual intentional structure which can be ideally represented as a vector pointing to any direction. In rare 
cases the directions of the intentionality-vectors overlap, leading people to structure a potential sub-group. In order for this sub-group to be formed effectively, a number of requirements must be met $[38,39]$ : for example, the frequency of interaction, the sharing of rules, the existence of a system which assigns roles, the pursuit of a common objective. Therefore, in this first phase there is identification between the individuals according to their intention directed towards the present time: at this moment their intentions directed towards the future are not yet being taken into consideration, but the subjects must be able to "read" at least a part of the others' intentions.

The frame - in this phase - is not called into question, nor can we foresee any element for a possible transformation of the shared context into something else: we must wait for the second phase in the emergence of networked flow for this to happen.

\section{Phase 2: Reducing the Distance}

In this second phase something new happens: the perception of similarities between the people who share the same direction of the intention-vector. The perception of similarities triggers an important dynamic which we have defined "reducing the distance". Individuals, having perceived these similarities, tend to prefer to interact with each other and to become aware of more and more similarities between them and in their motivations.

In this phase the individual still perceives a certain dissatisfaction regarding his personal present intention, caused by the perception of non-compliance regarding intentions directed towards the future. The subject recognizes that the other subjects he comes across in Phase 1 are experiencing the same sense of dissatisfaction, and this mutual dissatisfaction leads - on a structural level - to the creation of a sub-group which finds itself in a situation of liminality. People start to get close to one another and begin to form a sub-group: selfdefinition causes the identity-making identification to grow, and it is probable that the feeling of fulfillment when participating in the sub-group will increase in parallel. As noted by Searle [40], social groups are able to express their so-called "collective intention": they are not only guided by cooperation, but also by the genuine sharing of mental states such as beliefs, wishes, intentions. It is therefore probable that among the members of the new sub-group there is a growing perception of a common finality, although this may not be directly expressed or transformed into a goal. However, the sub-group does not yet put itself in direct contrast with the group (or better, with the frame) of reference: instead, it acts in terms of minority influence and draws on its persuasive skills [41, for a summary] in order to influence and to affect, in some way, the general direction of the frame.

\section{Phase 3: The Liminality-Parallel Action}

In this third phase we can theorize that the newly created sub-group, after reducing the distance, begins to consolidate its "boundaries" with respect to the pre-existing frame, and to position its common "intention-vectors" in a direction which enables the sub-group to close in on the limits of the pre-existing frame. The members of the original frame diminish in importance in the eyes of the new group's members, and they therefore begin to lose importance for the frame's boundaries. Returning to Goffman's theory, we can say that the members of the new sub-group - supported by satisfying interactions, by a now-clear sense of a common finality, by the sharing of intentions - begin to transform their group (or better, the potential structure of their group) into something resembling a new frame. The participants structure their experiences according to a common interpretative pattern, they establish conventions to indicate the boundaries of their transformation and finally through this process they are able to radically transform the meaning of the previous experience.

On one hand it is necessary that the group members experience a high level of social presence: the sensation of sharing objectives and emotions with others. On the other, it is also necessary that the group members experience the situation of liminality and identify within the group the means to overcome it. This allows for the emergence of a collective intention, which, moreover, becomes the group's first creative act in potential networked flow at the moment when they break definitively with the pre-existing frame and advance towards the new one. The previous balance is upset, and the sub-group completely redefines its state, thus creating the basis for a new and completely innovative frame with respect to the previous. The group is therefore freed from the control of the pre-existing social reality and is balanced internally. In this phase a leader figure has not yet emerged, the parameters for a common goal have not yet been defined and the group is still working towards finality as opposed to goal.

\section{Phase 4: Networked Flow}

In this phase we enter into what we have defined as networked flow: an "optimal" collective experience $[11,15]$ which defines members of a group and guides their actions. The new group identifies one or more leaders, who we can define, in this context, as the individual or individuals who are better able than the others to transform what was previously only finality, into goal. The leader/s exercises his influence over the group and thus helps in clarifying the group's objectives and facilitating its cohesion. The preexisting frame is abandoned, and a new frame, which provides a more valid background in which to support the group's creative activity, is established. It may be worthwhile noting that in this phase the key defining feature of networked flow may be the quality of the experience perceived by the participants: a state of mind characterized by a high level of concentration, involvement, control of the situation, clarity of objectives, intrinsic motivation and a positive emotional state.

In this phase there are several critical events which bring about the onset of networked flow:

- The transformation of the collective intention into a collective action;

- $\quad$ The internalization of the collective intention directed towards the future;

- The balance between the resources available to the group and those required by the common action;

- $\quad$ The identification of one or more leaders;

- $\quad$ The new frame must be made explicit. 


\section{Phase 5: Networked Flow - Creation of the Artifact}

It is our opinion that the group, once it has reached a state of networked flow and remains there at length, must in some way "substantiate" its common activity in the form of a product (meme) originating from that collective activity. This product may be an object, a thought, a theory, a custom which is taken up by the group (a parallel could be drawn with the concept of "community of practice"; [42]); a concrete or abstract artifact which did not exist before. The group in networked flow is therefore characterized by the adoption (or use) of the new artifact - and this aspect represents a further element of differentiation from the previous frame. Individual intentions directed towards the future are fully recognized in the collective action of the group in networked flow. The collective action is now measured in terms of effectiveness: networked flow must result in the production of a new and relevant artifact which represents the embodiment of the collective intention (and subordinate to the collective action). At this stage, however, the artifact is solely and exclusively relevant to the group itself: this is not network sharing since the artifact has not yet been applied outside the frame.

\section{Phase 6: Networked Flow - The Application of the Artifact in a Social Network}

Once the artifact has been created the group enters into the sixth and last phase, in which the artifact is taken into the pre-existing social network. At this point, the group in networked flow must make itself known to the world (which means it must take up a position in the network); and consequently the artifact also needs to be recognizable.

We can therefore surmise that contact with other groups and/or individuals is crucial, otherwise the effect of networked flow will remain unsuccessful. Although stages 4 and 5 can be defined as networked flow, it is only in this phase that we are able to speak specifically in terms of network, since:

- The artifact embodies the collective intention directed towards the future, and is able to inform other groups, leading them to adopt the same collective intention as the original group in networked flow. This process can be understood in the light of the stigmergy mechanism theorized by Pierre-Paul Grasse in 1959 $[12,43]$ to explain how insects manage to coordinate themselves in order to produce highly complex structures.

- At this point, logical progression takes us back to phase 1 of this model, with the difference that the focus of analysis is now directed towards the group and no longer towards the individual: the "circles" with the vector are no longer individuals but groups, and the surrounding "frame" is no longer the boundary of the social group, but of the extended network of reference.

\section{USING SOCIAL NETWORK ANALYSIS TO MODEL THE STRUCTURAL DYNAMICS OF INTERACTION IN CREATIVE LEARNING TEAMS}

In previous sections, we have proposed "networked flow" as a conceptual framework for integrating the concepts of group flow [11, 15], collaborative zone of proximal development [16] and social presence [31-33]. The inclusion of the adjective "networked" in the definition of this framework is indicative of our attempt to adopt a more inclusive definition of the creative collaboration process, which emphasizes the importance of socio-contextual variables and takes into account the role of virtual collaboration technologies. The challenge now becomes to identify an appropriate methodology which can be used to characterize and investigate the socio-interactional aspects involved in the creative collaboration process. Social Network Analysis (SNA) provides a useful approach for addressing this objective. The main advantage of SNA is that it considers individuals as interdependent units as opposed to autonomous elements, and thus it is particularly appropriate for studying group dynamics, as well as for investigating the role played by the individuals within these dynamics [44, 45]. In particular, the adoption of SNA can provide a deeper understanding about the factors that shape the interplay between individual creativity and the larger socio-cultural context, as well as to identify discernable social network characteristics associated with different levels of creativity $[46,47]$. SNA focuses on various aspects of the relational structures and the flow of information which characterize a network of people, by using two types of interpretation [44, 48]: graphs (or sociograms) which plot the dots (people) and their social relationships (edges); and structural indices, which depict quantitatively the network of social relations, analyzed on the basis of a variety of characteristics (eg. neighborhood, density, centrality, centralization, cohesion, etc.). SNA is based upon the flow of messages being sent and received by each pairs of individuals of the network, which are conceived and mutually dependent entities (i.e., each message sent by $\mathrm{X}$ to $\mathrm{Y}$ is also a message received by $\mathrm{Y}$ from $\mathrm{X})$. For each structural characteristic of a relational network, SNA provides two types of indices: individual indices (i.e. based on relations and exchanges characterizing each actor of the networks) and group indices (i.e. based on relations and exchanges characterizing the network as a whole). Studies that have applied SNA to creativity research have mainly focused on the relationship between group performance and indices such as centrality and density [49]. For example, Cattani and Ferriani [47] applied SNA to investigate the network of collaborations within the Hollywood motion picture industry over the period 19922003. To reconstruct individual and team level networks, these authors used archival sources listing every professional involved in the movies included in the sample and created variables at the individual, team and project levels. Results of this longitudinal analysis indicated two key mechanisms that regulate the relationship between socio-relational system and individuals' creative performance. The first aspect concerns the relative position of individuals in the larger social system. According to Cattani and Ferriani, individuals who span the boundaries between the core and the periphery of the social system are in a vantage position to enhance their creative performance. On one hand, the closeness to the core allows them to be directly exposed to sources of social legitimacy and support, which are crucial factors to sustain creative performance. On the other hand, by mixing with the periphery of the network, they can gather fresh and new inputs that are more likely to be generated on the border of 
the social system, while avoiding the conformity pressures that are typical of a established and consolidated field. The second aspect highlighted by Cattani and Ferriani's study is that occupying intermediate position is a useful, but not necessary condition for enhancing individual creativity. Extreme positions (core or periphery) can be balanced by participating in teams that combine core and peripheral actors. To illustrate this mechanism, the authors consider the example of two individuals - one closer to the core and the other closer to the fringe of the network - that decide to collaborate. In this situation, the two individuals are exposed both to the core and the periphery and therefore have a higher chance of enjoying the benefits accruing to that position by working together rather than remaining separate. Another example of application of SNA to creativity research is provided by Kidane and Gloor [50], who used this approach for investigating the temporal communication patterns of online communities of developers and users of an open source software. They measured the productivity of each community, and attempted to correlate group communication characteristic and productivity attributes. Findings indicated a significant correlation between specific social networks properties (in particular density and betweenness centrality) and group productivity measures (performance and creativity).

Other studies have used SNA specifically to investigate creativity and knowledge production in educational contexts. For example, Mazzoni and Gaffuri [48] used this approach for monitoring student's activities in Computer-Supported Group-Based Learning (CSGBL). One of the main challenges of CSGBL is to develop procedures that allow to measure, at the same time, the performance achieved by each student, the performance of the group as a whole, and the individual contributions to the collective outcome [51]. To this end, a SNA model was defined and applied in the study of a CSGBL-based formative activity involving first-year students enrolled in the Faculty of Psychology at the University of Bologna. The SNA model was designed to analyze the influence of relational structures (the Structural Profile of Interpersonal Skills, SPIS) on students' improvements on a learning task measured either at the individual ("Actor-SPIS", derived from the individual SNA indices) or group ("Group-SPIS" derived from SNA indices) levels. The study found that only students with a high ActorSPIS made a significant improvement, and that only groups characterized by high density and low centralization made significant progress [48]. In another study, Mazzoni [52, 53] analyzed whether specific SNA indices measuring social presence are possible predictors of the performance of a creative learning network. In this study, groups of adults (tutors and teachers) on a post-graduate course interacted using the Synergeia Web Platform (a web-based system designed to support collaborative learning processes). The task assigned to the groups consisted in the development a common project concerning teaching (elaborating a plan, designing a product, constructing a repository, a problem solving or a case study). The product of each group was assessed (using a blind peer-review procedure) by two referees who evaluated the degrees of originality and transferability of the different projects. A special SNA index - the Cliques Participation Index (CPI) was thus created for measuring the level of social presence within each group.
The findings of this study showed that the projects that received higher creativity ratings were produced by those groups characterized by higher levels of social presence, as measured through the CPI index. As well as for the previous study, these results suggest the potential of SNA as a methodology to study the structural features of creative learning networks. Although till now we have presented the use of SNA indices for comparing groups on the basis of their different structure of interactions, SNA indices allow us to analyze groups in longitudinal way for describing and investigating the evolution of the structure of interaction within a group. The longitudinal use of SNA is specifically interesting if we consider the evolution of the networked flow process and the dynamics (cohesion, leadership, segregation) that this process involves as it unfolds over time. From this point of view, SNA can provide specific measures for all these basic dynamics (e.g. the cohesion and cliques index for cohesion, the centrality and centralization indices for the leadership and the EI index or the SMI index for the segregation) that allows monitoring and analyzing the evolution of the process and to identify a specific phase of the process. For example, Mazzoni and Ponti [54] used this approach for analyzing the evolution of relations between members of a professional social network; moreover, at the moment of writing this paper, another study is being carried out by our team with the purpose of analyzing the structural dynamics of small groups of university students engaged in creative collaboration tasks occurring in a blended learning context. Preliminary findings show that those groups presenting, from a structural viewpoint, the typical evolution described by the networked flow model, are characterized by better creative performance than the other groups.

\section{TOWARD A UNIFIED THEORY OF CREATIVE LEARNING NETWORKS: DIRECTIONS FOR FUTURE RESEARCH}

As we have seen, social network theory can be a useful tool for studying creative collaboration as it allows us to interrelate the characteristics that we observe at a structural level with specific features of the creative process. However, the main limits of this approach lies in the fact that in social network analysis, the characteristics of the individual are less relevant than the relationships (and the dynamics of the relationships) that the individual has with the other members of the network. By favoring the analysis of structural properties over psychological features, social network analysis enables us to describe the characteristics of a creative learning network in a strictly mathematical way, but at the same time it places limits on the explanation of the factors which determine this evolution. For example, social network analysis permits us to identify the structural differences between two teams which have different creative skills, but it does not provide an explanation for such differences. The reason is that, by definition, the unit of measurement in social network analysis is not the individual, but the relationship between individuals, which can be defined in a variety of ways (as a communicative act, an acquaintance, friendship, family, etc.). Nonetheless, as we have pointed out in the introductory sections of this article, the investigation of psychological dynamics involved in optimal group collaboration is not less important than the understanding of the interactional dynamics. In particular, 
our reflection is based on the conviction that by investigating the close relationship existing between social presence and group flow it is possible to create an heuristic bridge between quality of experience, action, communication and culture in explaining the factors that promote effective creative collaboration within a learning team.

A future challenge is therefore to succeed in developing a framework which can integrate the "structural" dimension (determined by the sum of the formal-morphological characteristics) with the "functional" dimension (determined by the sum of the psycho-social processes) in the study of creative learning networks. We believe that the adoption and further development of the networked flow model can have significant implications for the study of creative collaboration in educational settings. First, the model can offer new insights about the way in which creative learning teams assemble, and how they evolve over time to form potentially broader creative learning networks. Second, the investigation of the networked side of creative learning teams can help in identifying which psychological, contextual and socio-interactional factors lead to emergence of optimal group performance, therefore allowing the definition of training strategies that incorporate these factors. Last - but not least - the adoption of the networked flow approach has practical methodological advantages, since it can be effectively applied to investigate creative collaboration in blended educational contexts, where physical and virtual environments are combined to support the learning process.

\section{ACKNOWLEDGEMENT}

None declared.

\section{CONFLICT OF INTEREST}

None declared.

\section{REFERENCES}

[1] Florida R. The rise of the creative class: and how it's transforming work, leisure and everyday life. New York: Basic Books 2002.

[2] Scardamalia M, Bereiter C. Computer support for knowledgebuilding communities. J Learn Sci 1994; 3(3): 265-83.

[3] Craft A. Creativity in schools: tensions and dilemmas. London: Routledge/Falmer 2005.

[4] Seltzer K, Bentley T. The creative age: knowledge and skills for the new economy. London: Demos 1999.

[5] Lave J, Wenger E. Situated learning: legitimate peripheral participation. Cambridge, UK: Cambridge University Press 1991.

[6] Scardamalia M, Bereiter C. Computer support for knowledgebuilding communities. J Learn Sci 1994; 3(3): 265-83.

[7] Nunn CE. Discussion in the college classroom: Triangulating observational and survey results. J High Educ 1996; 67(3): 243-66.

[8] Johnson DW, Johnson R.T. Cooperative learning and the achievement and socialization crisis in science and math classroom. In: Champagne AB, Hornig LE, Eds. Students and Science Learning. Washington, DC: AAAS 1987.

[9] Sullivan FR. Serious and playful inquiry: epistemological aspects of collaborative creativity. Educ Technol Soc 2011; 14(1): 55-65.

[10] Eteläpelto A, Lahti J. The resources and obstacles of creative collaboration in a long-term learning community. Thinking Skills Creativity 2008; 3: 226-40.

[11] Sawyer RK. Group genius: the creative power of collaboration. New York: Basic Books Press 2007.

[12] Elliott M. Stigmergic Collaboration: the evolution of group work. J Media Cult 2006; 9(2). [Accessed on line: February 24, 2010].

[13] Vygotsky LS. Mind in society: the development of higher psychological processes. Cambridge, MA: Harvard University Press 1978.
[14] John-Steiner V, Mahn H. Sociocultural approaches to learning and development: A Vygotskian framework. Educ Psychol 1996; 31 (34): 191-206.

[15] Sawyer K. Group creativity: Music, theatre, collaboration. Mahwah, NJ: Erlbaum 2003.

[16] Armstrong AC. The fragility of group flow: The experiences of two small groups in a middle school mathematics classroom. J Math Behav 2008; 27: 101-15.

[17] Csikszentmihalyi M. Beyond boredom and anxiety. San Francisco: Jossey-Bass 1975.

[18] Csikszentmihalyi M. Beyond boredom and anxiety: experiencing flow in work and play. New York: Jossey-Bass 2000.

[19] Massimini F, Delle Fave A. Individual development in a biocultural perspective. Am Psychol 2000; 55(1): 24-33.

[20] Delle Fave A, Massimini F, Bassi M. Education, learning, and cultural transmission. In: Delle Fave A, Massimini F, Bassi M, Eds. Psychological selection and optimal experience across cultures: social empowerment through personal growth. Cross-cultural advancements in positive psychology 2011;2(2) pp. 235-52.

[21] Egbert J. A study of flow theory in the foreign language classroom. Modern Language Journal 2003; 87: 499-518.

[22] Shernoff DJ, Csikszentmihalyi M, Schneider B, Shernoff ES. Student engagement in high school classrooms from the perspective of flow theory. Sch Psychol Quart 2003; 18(2): 158-76.

[23] Mandigo JL, Thompson L. Go with their flow: How flow theory can help practitioners to intrinsically motivate children to be physically active. Phys Educ 1998; 55: 145-59.

[24] Abbott JA. "Blinking out" and "having the touch" two fifth-grade boys talk about flow experiences in writing. Written Commun 2000; 17(1): 53-92.

[25] Custodero L. Seeking challenge, finding skill: Flow experience in music education. Arts Educ Policy Rev 2002; 103(3): 3-9.

[26] Davis B, Simmt E. Understanding learning systems: Mathematics education and complexity science. J Res Math Educ 2003; 34 (2): 137-67.

[27] Biocca F. The Cyborg's Dilemma: Progressive embodiment in virtual environments. In: Marsh JP, Gorayska B, Mey JL, Eds. Humane interfaces: questions of method and practice in cognitive technology. Amsterdam, The Netherlands: Elsevier 1999; pp. 11342 .

[28] Spagnolli A, Gamberini L. Immersion/Emersion: Presence in hybrid environments. Proceedings of Presence 2002: Fifth Annual International Workshop, Porto, Portugal 2002.

[29] Spagnolli A, Gamberini L. A Place for Presence. Understanding the Human Involvement in Mediated Interactive Environments. PsychNology Journal 2005; 3(1): 6-15. Retrieved 2010 February 17, from: http://207.210.83.249/psychnology/File/PSYCHNOLOG Y JOURNAL 3 1 SPAGNOLLI.pdf

[30] Spagnolli A, Varotto D, Mantovani G. An ethnographic actionbased approach to human experience in virtual environments. Int $\mathbf{J}$ Hum Comput Stud 2003; 59(6): 797-822.

[31] Riva G, Anguera MT, Wiederhold BK, Mantovani F. From communication to presence: cognition, emotion and culture towards the ultimate communicative experience. Amsterdam: IOS Press 2006.

[32] Riva G, Waterworth JA, Waterworth EL, Mantovani F. From intention to action: The role of presence. New Ideas Psychol 2011; 29(1): 24-37.

[33] Waterworth JA, Waterworth EL, Mantovani F, Riva G. On feeling (the) Present: An evolutionary account of the sense of presence in physical and electronically-mediated environments. J Consciousness Stud 2010; 17(1-2): 167-78.

[34] Rizzolatti G, Sinigaglia C. So quel che fai. Il cervello che agisce e i neuroni specchio. Milano: Raffaello Cortina 2006.

[35] Rizzolatti G, Fadiga L, Gallese V, Fogassi L. Premotor cortex and the recognition of motor actions. Cogn Brain Res 1996; 3: 131-41.

[36] Damasio A. Self comes to mind: Constructing the conscious brain. New York: Knopf Doubleday Publishing Group 2010.

[37] Goffman E. Frame Analysis. An essay on the Organization of Experience. New York: Harper and Row 1974.

[38] Rubin JZ. Introduction. In: Swap C. Ed. Group Decision Making, Beverly Hills: Sage 1984.

[39] McGrath JE. Groups: Interaction and performance. Englewood Cliffs: Prentice-Hall 1984.

[40] Searle JR. The construction of social reality. London: Penguin Books 1995. 
[41] O'Keefe DJ. Persuasion: Theory and research. $2^{\text {nd }}$ ed. Newbury Park: Sage 2002.

[42] Wenger E. Communities of practice. Cambridge: University Press 1998.

[43] Grasse PP. La reconstruction du nid et les coordinations interindividuelles chez bellicositermes natalensis et cubitermes sp. La theorie de la stigmergie: essai d'interpretation du comportement des termites constructeurs. Insectes Sociaux 6; 1959: 41-81.

[44] Wasserman S, Faust K. Social network analysis. methods and applications. Cambridge University Press 1994.

[45] Scott J. Social network analysis: a handbook. $2^{\text {nd }}$ ed. London: Sage 2000.

[46] Guimerà R, Uzzi $\mathrm{B}$, Spiro $\mathrm{J}$, Amaral L. Team assembly mechanisms determine collaboration network structure and team performance. Science 2005; 308: 697-702.

[47] Cattani G, Ferriani S. A core/periphery perspective on individual creative performance: social networks and cinematic achievements in the Hollywood film industry. Organiz Sci 2008; 19(6): 824-44.

[48] Mazzoni E, Gaffuri P. Monitoring Activity in e-Learning: a quantitative model based on web tracking and Social Network Analysis. In: Juan AA, Daradoumis T, Xhafa F, Caballe S, Faulin $\mathrm{J}$, Eds. Monitoring and assessment in online collaborative environments: emergent computational technologies for E-learning Support 2009; pp. 111-30.
[49] Gloor P, Oster D, Raz O, Pentland A, Schoder D. The virtual mirror - reflecting on your social and psychological self to increase organizational creativity, J Int Stud Manag Organization 2010; (Summer) 40(2). Avialable from: http://papers.ssrn.com/sol3/pap ers.cfm?abstract_id=1327521 [Retrieved 2011 January 29].

[50] Kidane Y, Gloor P. Correlating temporal communication patterns of the Eclipse open source community with performance and creativity. Comput Math Org Theory 2007; 13(1): 17-27.

[51] Matteucci MC, Carugati F, Selleri P, Mazzoni E, Tomasetto C. Teachers' judgment from a European psychosocial perspective. In: Ollington GF, Ed. Teachers and teaching: strategies, innovations and problem solving. New York: Novascience 2008; pp. 31-55.

[52] Mazzoni E. Dalle azioni collettive alla qualità del rendimento: analisi strutturale di gruppi in formazione che collaborano in rete. Psicologia dell'Educazione e della Formazione 2007; 9(1): 99-118.

[53] Mazzoni E. Reti sociali... in rete: dal web tracking all'analisi di partecipazione e rendimento in gruppi collaborativi in rete. In D’Esposito MR, Giordano G, Vitale MP, Eds. Analisi delle Reti Sociali: per conoscere uno strumento, uno strumento per conoscere. Atti del Workshop ARS'07. Catanzaro: Rubbettino Editore Srl. 2009.

[54] Mazzoni E, Ponti P. Personal Learning Environment e Lifelong Learning: un'indagine descrittiva delle dinamiche interattive in un social network. J e-Learning Knowledge Society 2008; 2: 99-108.

Received: May 7, 2011

Revised: June 14, 2011

Accepted: July 25, 2011

(C) Gaggioli et al.; Licensee Bentham Open.

This is an open access article licensed under the terms of the Creative Commons Attribution Non-Commercial License (http://creativecommons.org/licenses/by-nc/ 3.0/) which permits unrestricted, non-commercial use, distribution and reproduction in any medium, provided the work is properly cited. 